\title{
Influence of indocyanine green angiography on microsurgical treatment of spinal perimedullary arteriovenous fistulas
}

\author{
Keisuke Takai, MD, PhD, ${ }^{1}$ Hiroki Kurita, MD, PhD, ${ }^{2}$ Takayuki Hara, MD, PhD, ${ }^{3}$ \\ Kensuke Kawai, MD, PhD, ${ }^{4}$ and Makoto Taniguchi, MD, PhD ${ }^{1}$ \\ 1'Department of Neurosurgery, Tokyo Metropolitan Neurological Hospital, Tokyo; 2Department of Cerebrovascular Surgery, \\ International Medical Center, Saitama Medical University, Saitama; ${ }^{3}$ Department of Neurosurgery, Toranomon Hospital, Tokyo; \\ and ${ }^{4}$ Department of Neurosurgery, NTT Medical Center, Tokyo, Japan
}

\begin{abstract}
OBJECTIVE The microvascular anatomy of spinal perimedullary arteriovenous fistulas (AVFs) is more complicated than that of dural AVFs, and occlusion rates of AVF after open microsurgery or endovascular embolization are lower in patients with perimedullary AVFs (29\%-70\%) than they are in those with dural AVF $(97 \%-98 \%)$. Reports of intraoperative blood flow assessment using indocyanine green (ICG) video angiography in spinal arteriovenous lesions have mostly been for spinal dural AVFs. No detailed reports on spinal perimedullary AVFs are available.
\end{abstract}

METHODS Participants were 11 patients with spinal perimedullary AVFs (Type IVa in 5 patients, Type VIb in 4, and Type IVc in 2). Intraoperative ICG video angiography was assessed by measuring the number of cases in which this modality was judged essential by the surgeon to correctly occlude the fistula.

RESULTS In all patients, arterial feeders were identified and intravenous ICG video angiography was performed before and after blocking the feeders. In one patient, selective intraarterial ICG video angiography was also performed. The findings provided by ICG video angiography significantly changed the surgical procedure in 4 of 11 patients (36\%). Postoperatively, complete occlusion of the AVF was achieved in 10 of the 11 patients (91\%).

CONCLUSIONS Intraoperative ICG video angiography can have a significant impact on deciding surgical strategy in the microsurgical treatment of spinal perimedullary AVF.

http://thejns.org/doi/abs/10.3171/2015.12.FOCUS15574

KEY WORDS arteriovenous malformation; dural arteriovenous fistula; arteriovenous shunt; angioarchitecture; pathology; endovascular treatment; surgical treatment

$\mathrm{S}$ PINAL arteriovenous (AV) lesions can be classified into 4 major types according to the vascular anatomy of AV connections and their relationships with the neural structures: dural arteriovenous fistula (AVF), ${ }^{16,17}$ intramedullary AV malformation, ${ }^{19}$ perimedullary AVF,${ }^{20}$ and extradural AVF. ${ }^{18}$

Spinal dural AVFs are the most common and are characterized by direct $\mathrm{AV}$ connections between meningeal arteries and a radiculomedullary vein on the spinal dura mater. ${ }^{17}$ Perimedullary AVFs are characterized by direct $\mathrm{AV}$ connections between pial branches of the anterior and/ or posterior spinal arteries and pial veins without an intervening nidus on the surface of the spinal cord. ${ }^{6}$

Because the microvascular anatomy of perimedullary AVFs is more complicated than that of dural AVFs, complete occlusion rates of AVFs after open microsurgery or endovascular embolization are lower in patients with a perimedullary AVF $(29 \%-70 \%)^{3,10,11,21}$ than in those with a dural AVF (97\%-98\%). ${ }^{2,14}$

As an intraoperative imaging modality, indocyanine green (ICG) video angiography, has been introduced for spinal AV lesions, but most such studies have examined

ABBREVIATIONS $A S A=$ anterior spinal artery; $A V=$ arteriovenous; $A V F=A V$ fistula; $I C G=$ indocyanine green; $P S A=$ posterior spina artery.

SUBMITTED November 1, 2015. ACCEPTED December 8, 2015.

INCLUDE WHEN CITING DOI: 10.3171/2015.12.FOCUS15574. 
spinal dural AVFs, and few studies have reported on spinal perimedullary AVFs. ${ }^{5,7,12,13}$

The purpose of the present study was therefore to assess the influence of intraoperative ICG video angiography on deciding surgical strategy in the microsurgical treatment of spinal perimedullary AVFs.

\section{Methods}

This study protocol was approved by the institutional review board at Tokyo Metropolitan Neurological Hospital. Since this was a retrospective, noninvasive study, the need for written informed consent was waived by the review board. A public notice that provided information on this study was instead provided on the website of Tokyo Metropolitan Neurological Hospital.

\section{Patient Population}

The total population of patients included 11 patients with spinal perimedullary AVF treated between April 2011 and October 2015 at 4 institutions (Table 1): Tokyo Metropolitan Neurological Hospital $(\mathrm{n}=7)$; the International Medical Center at Saitama Medical University $(\mathrm{n}=$ 2); Toranomon Hospital $(\mathrm{n}=1)$; and NTT Medical Center $(\mathrm{n}=1)$. All patients were treated microsurgically by the first author (K.T., $n=8$ ) or other authors (H.K., T.H., or K.K., $n=3$ ) under the direction of the first author, a Japanese Spinal Surgery Society board-certified spine neurosurgeon. Of the 11 patients 4 were men and 7 were women, whose median age was 63 years (range $2-83$ years).

\section{Assessment of ICG Video Angiography}

In the 10 adult patients, ICG (12.5 mg in $5 \mathrm{ml}$ of saline) was injected intravenously before and after blocking feeders or a draining vein. In the remaining patient, a pediatric patient, a smaller amount of ICG (2.5 $\mathrm{mg}$ in $1 \mathrm{ml}$ of saline) was injected. In one patient, selective intraarterial injections of diluted ICG $(0.075 \mathrm{mg}$ in $3 \mathrm{ml}$ of saline) were also performed using an angiographic catheter through a metallic introducer sheath $(45 \mathrm{~cm}$ long) placed into the femoral artery before surgery. ${ }^{22}$ Intraoperative ICG video angiography was performed using a laser-fluorescence imaging device integrated in the surgical microscope.

The usefulness of intraoperative ICG video angiography was assessed in terms of whether the surgeon's findings without ICG video angiography (i.e., vessel color change with inspection, blood flow on microvascular Doppler ultrasonography, or intraoperative angiographic findings) corresponded to findings on ICG video angiography. The influence of ICG on surgical strategy was assessed by measuring the number of cases in which ICG video angiography was judged essential by the surgeon to correctly occlude the fistula.

\section{Results}

Spinal levels of involvement in perimedullary AVFs were as follows: cervical cord or root in 3 patients, lumbar enlargement or the conus medullaris in 5, and the filum terminale in 3 (Table 1). In one patient with a perimedullary AVF on the cervical cord, the main feeding arter- ies were pial branches of an anterior spinal artery (ASA) fed directly by the vertebral artery. Because multiple pial branches flowed into AVFs and blood flow was high, this lesion was classified as Subtype IVb according to the system described by Anson and Spetzler. ${ }^{1}$ In 2 patients with perimedullary AVFs on the cervical root, the main feeding structure was a radicular artery from the vertebral or ascending cervical artery through the intervertebral foramen. The AVF was also fed by the same radicular artery from the ASA through the pial plexus on the spinal cord. Because the feeding artery was single and blood flow was low, these lesions were classified as Subtype IVa. In 5 patients with perimedullary AVFs on the lower portion of the spinal cord, the main feeding arteries were pial branches of the ASA fed by the artery of Adamkiewicz. In 4 of these 5 patients, pial branches of the posterior spinal artery (PSA) fed by another segmental artery also flowed into the AVF. Three lesions were classified as Subtype IVb and the other 2 lesions with a large varix as Subtype IVc. In 3 patients with perimedullary AVFs on the filum terminale, the feeding structure was an artery of the filum terminale from the ASA or the lateral sacral artery. Because the feeding artery was single, these lesions were classified as Subtype IVa. Arteriovenous connections were located on the ventral surface of the spinal cord in 5 patients (1 cervical lesion and 4 lower spinal lesions), the surface of the spinal ventral root in 2 patients ( 2 cervical lesions), the dorsolateral surface of the spinal cord in 1 patient (lower spinal lesion), and the surface of the filum terminale in 3 patients (filum lesions).

During surgery, a posterolateral or posterior approach through multilevel laminotomy or single-level laminectomy was performed, the feeders were identified, and ICG video angiography was performed before and after blocking the feeders. In one patient, selective intraarterial ICG video angiography was also performed.
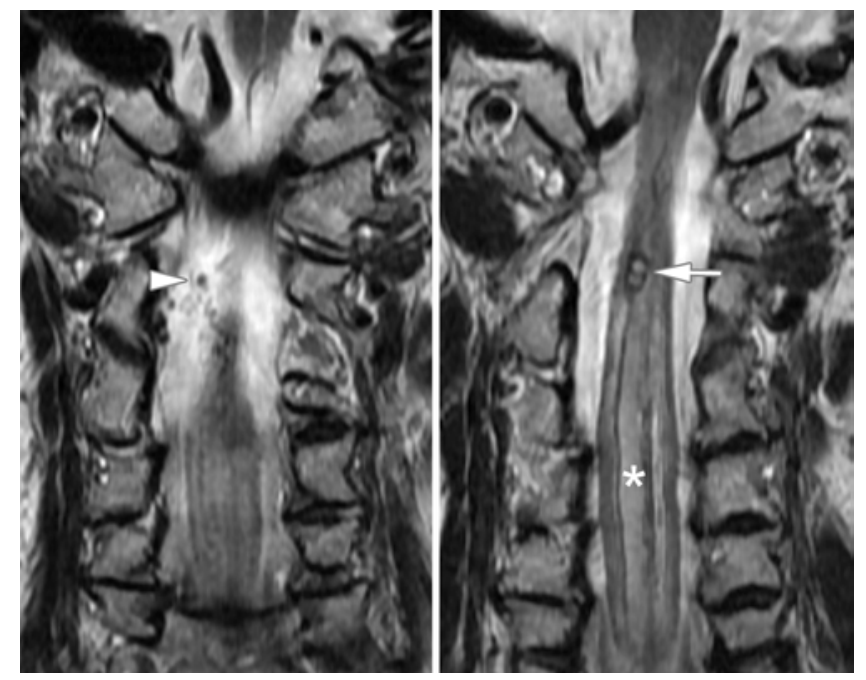

FIG. 1. Patient 1. Coronal images of T2-weighted MRI showing two aneurysms: an aneurysm and abnormal vessels in the subarachnoid space (arrowhead, left) and an aneurysm under the pia mater (arrow, right). Note the intramedullary hemorrhage extending from the medulla to the upper thoracic level (asterisk, right). 


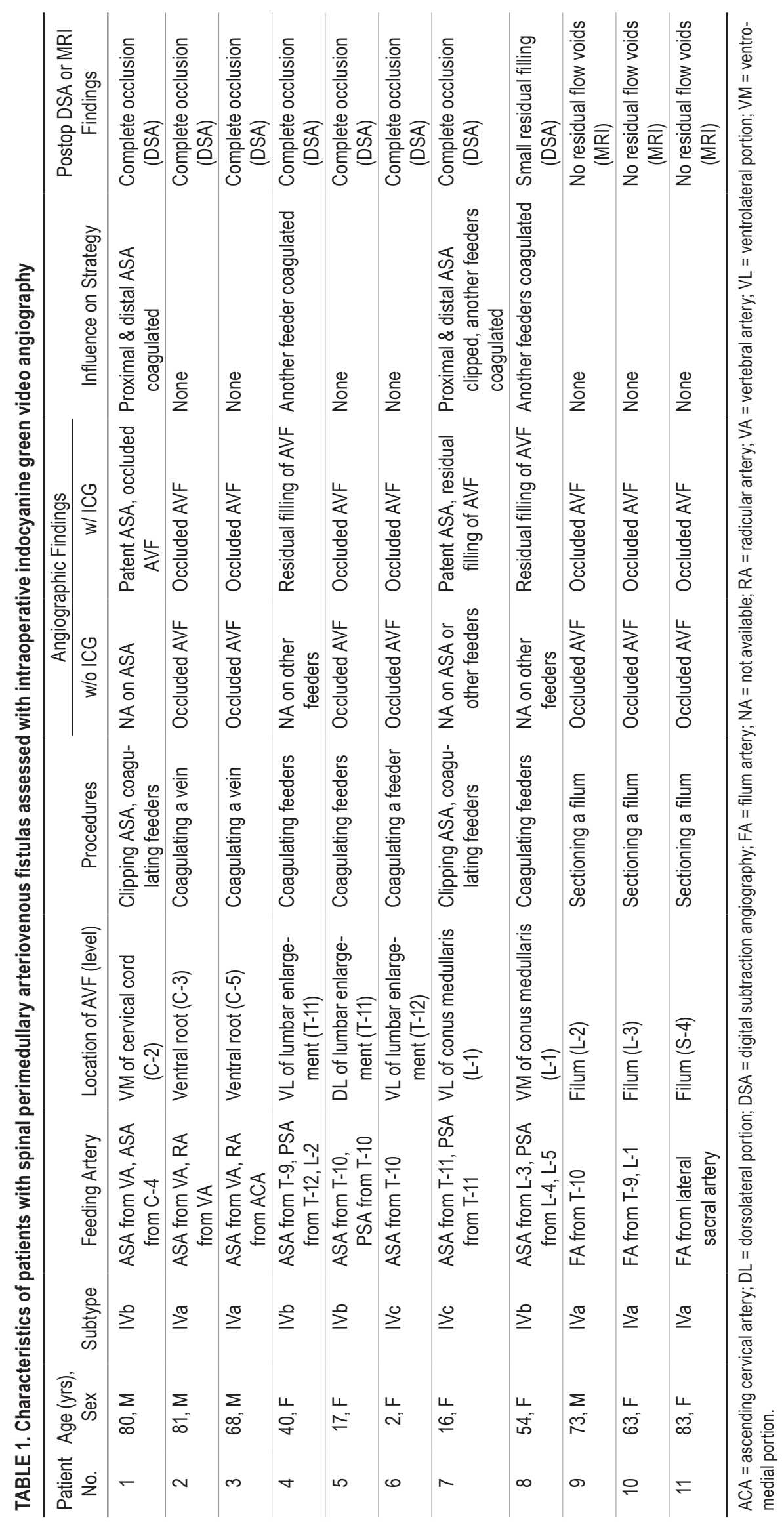




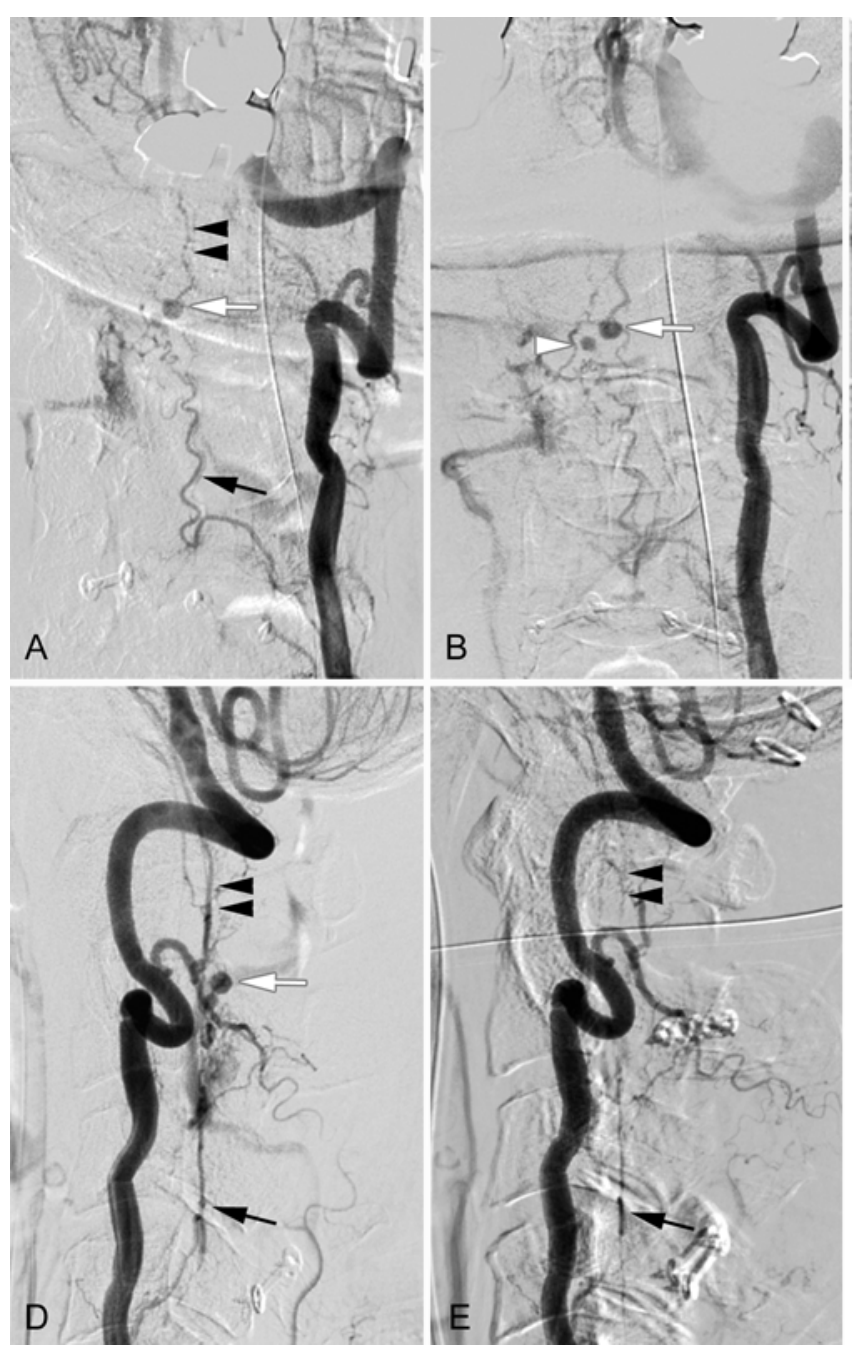

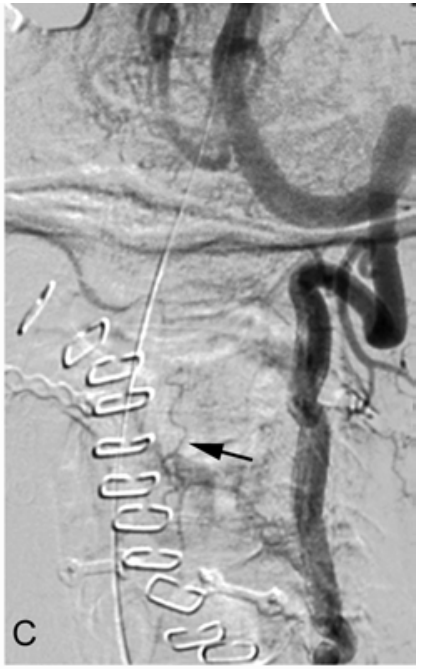

FIG. 2. Patient 1. Preoperative spinal angiograms (A, B, and D) showing that the feeding arteries are pial branches of the ASA fed directly by the vertebral artery (black double arrowheads, $A$ and D). The ASA is also fed by the left $\mathrm{C}-4$ radiculomedullary artery (black arrows, $A$ and $D$ ). Note the two aneurysms: the smaller one located in the subarachnoid space (white arrowhead, B) and the larger one located just under the pia mater (white arrows, $A, B$, and D). The AVF is located on the ventrolateral surface of the cervical cord just over the larger subpial aneurysm. The draining vein is the right $\mathrm{C}-3$ radiculomedullary vein. Postoperative angiograms ( $\mathrm{C}$ and $\mathbf{E})$ showing complete occlusion of the AVF and normal filling of the ASA (black double arrowheads and arrows, $\mathrm{C}$ and $\mathrm{E}$ ).
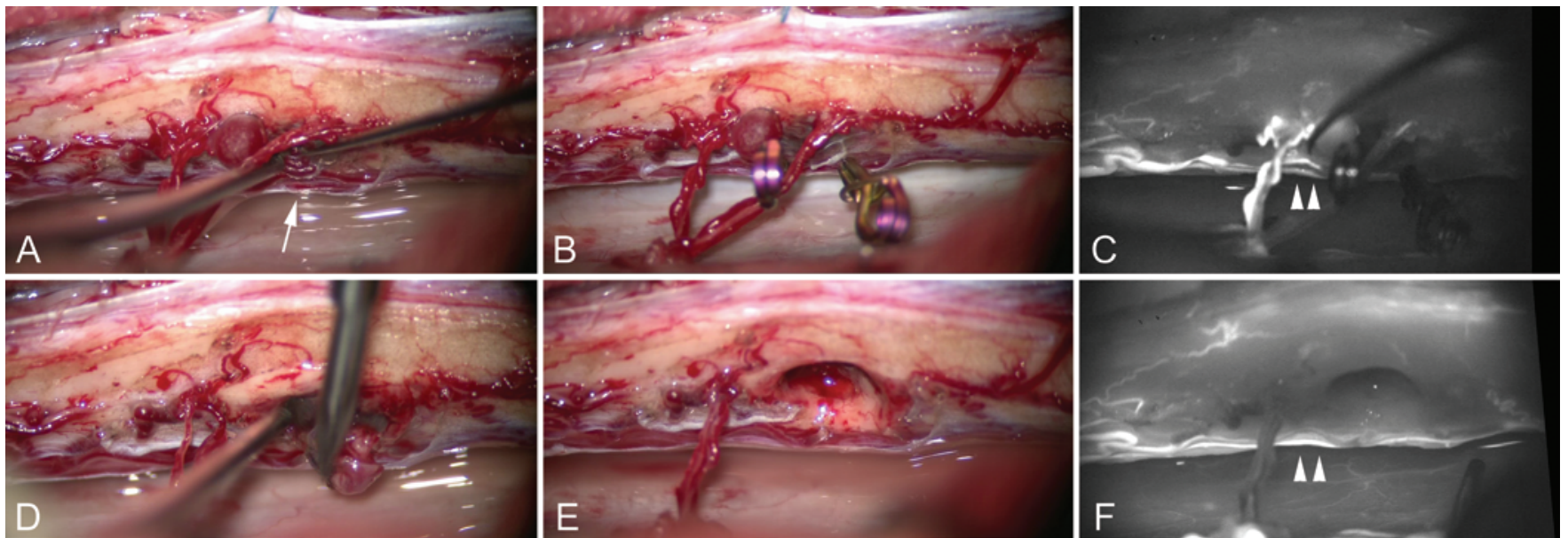

FIG. 3. Patient 1. Intraoperative photographs (A, B, D, and E) showing the AVF on the ventrolateral surface of the spinal cord (arrow in A), clipping of the proximal and distal ASA feeding the AVF (B), and resection of the AVF and associated aneurysms (D and E). Note that the AVF comprises direct AV connection between the ASA and a thin-walled abnormal vein (arrow, A). The vein is fed as in an endo-to-side anastomosis by the ascending and descending ASA. There is duplication of the ASA: one ASA feeding the AVF and the other ASA feeding the spinal cord. The ASA feeding the AVF is clipped temporarily at the proximal and distal portions (B). ICG video angiograms (C and F) showing complete occlusion of the AVF and normal filling of the other ASA feeding the spinal cord (arrowheads, $\mathrm{C}$ and $\mathrm{F}$ ). 
The findings provided by ICG video angiography significantly changed the surgical procedure in 4 of the 11 patients (36\%). After surgery, complete AVF occlusion was achieved in 10 of the 11 patients (91\%). In one patient, small residual filling was observed on postoperative angiography, although main feeding arteries from the ASA were occluded. We did not offer second surgery, because patient's symptoms (pain in the lower extremities) were completely resolved postoperatively.

\section{Illustrative Cases \\ Patient 1}

An 80-year-old man presented with tetraplegia due to intramedullary hemorrhage from perimedullary AVF on the ventral cervical spinal cord (Figs. 1 and 2). Emergency hematoma evacuation was performed via a posterior midline approach. Since the patient showed neurological improvements after the first surgery, a second surgery was performed 1 month later to prevent rebleeding. Neurological examination before the second surgery showed right hemiparesis and sensory disturbances below the C-2 dermatome on the right side.

A posterolateral approach was performed through a hemilaminotomy at the $\mathrm{C} 1-3$ levels. After rotating the spinal cord, the AVF fed by the ASA was identified on the ventral surface of the cervical cord (Fig. 2). Duplication of the ASA was also identified: one ASA fed the AVF and the other ASA fed the spinal cord and was not associated with the AVF. To occlude the AVF, the ASA feeding the AVF was clipped temporarily. Blood flow velocity in the ASA could not be recorded on microvascular Doppler, but ICG video angiography revealed occlusion of the ASA feeding the AVF and ascending flow in the other ASA with no time delay (Fig. 3). On the basis of ICG findings, the ASA feeding the AVF was permanently coagulated. No spinal cord infarction was observed on postoperative MRI, and no neurological deterioration was noted after the second surgery. Follow-up angiography showed complete occlusion of the AVF and normal filling of the ASA.

\section{Patient 7}

A 16-year-old girl presented with severe pain in the right lower extremity and urinary incontinence due to spinal cord compression due to the effect of a perimedullary AVF on the conus medullaris (Figs. 4 and 5).

A posterolateral approach was performed through a laminotomy at the T11-L1 level. Because the main pial feeding arteries branched off from the ASA in a cross shape, the left deeper vessel could not be exposed. To block both feeders, the ASA was temporarily clipped just proximal and distal to these pial branches. Blood flow velocity of the distal ASA could not be recorded on microvascular Doppler, but ICG video angiography revealed not only occlusion of pial feeding arteries but also ascending flow in the distal ASA with no time delay through the arterial basket of the conus medullaris (Fig. 6). On the basis of ICG findings, the ASA was permanently clipped just proximal and distal to the pial feeding arteries. No spinal cord infarction was observed on postoperative MRI and no postoperative neurological deterioration was noted.
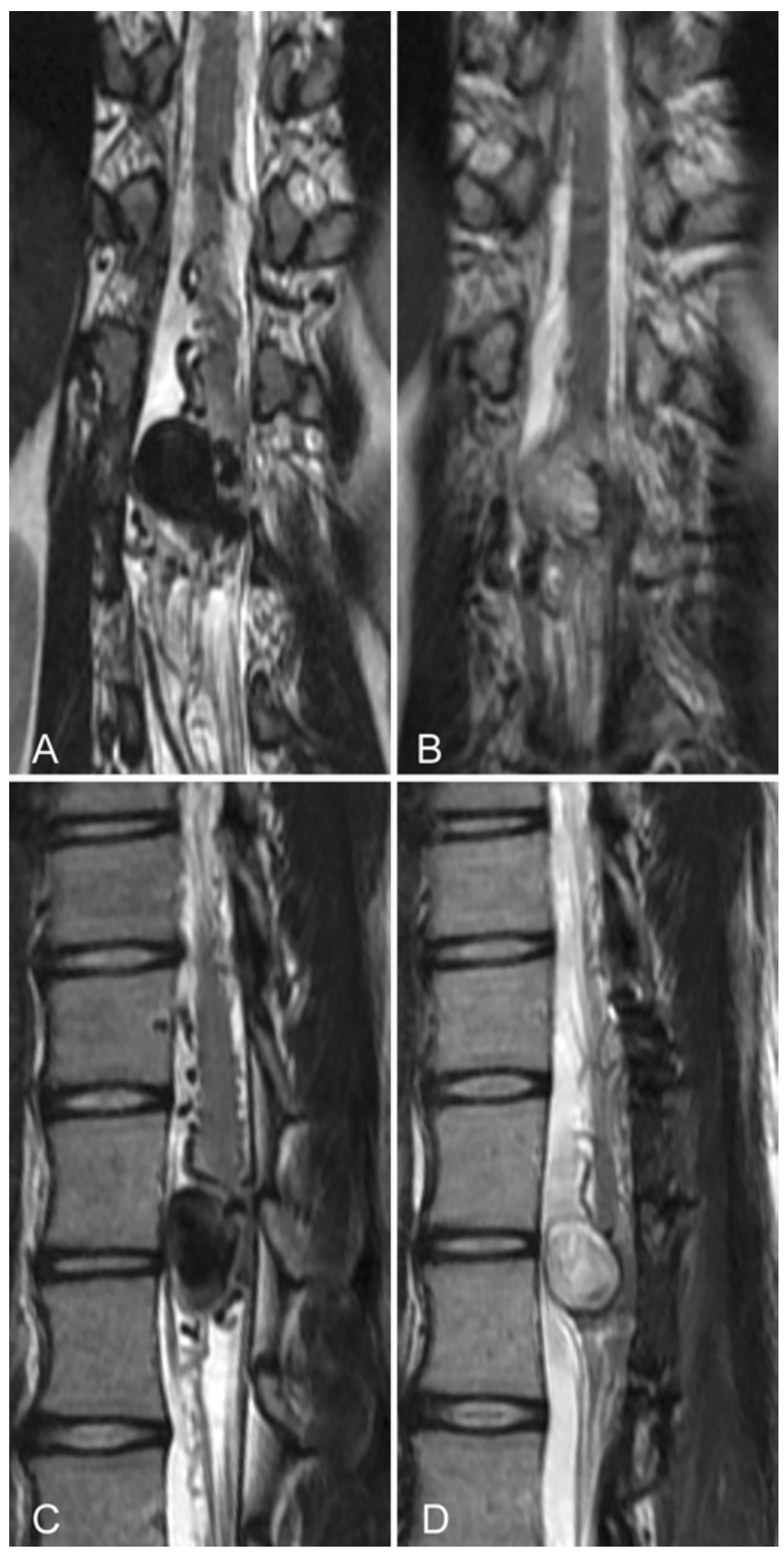

FIG. 4. Patient 7. Preoperative coronal (A) and sagittal (C) T2-weighted MR images showing a large varix and abnormal vessels around the $\mathrm{CO}^{-}$ nus medullaris. Postoperative coronal (B) and sagittal (D) T2-weighted MR images demonstrating the total thrombosis of the varix and reduction in size of the abnormal vessels.

The patient required a second surgery because new feeding arteries through the collateral circulation of the spinal cord were observed on postoperative angiography, although 5 feeding arteries had been clipped in the first surgery (Fig. 5). In the second surgery, intraoperative spinal angiography and selective intraarterial ICG video angiography were performed (Fig. 6). The quality of intraoperative spinal angiography did not allow assessment of the small pial feeding arteries. However, selective intra- 

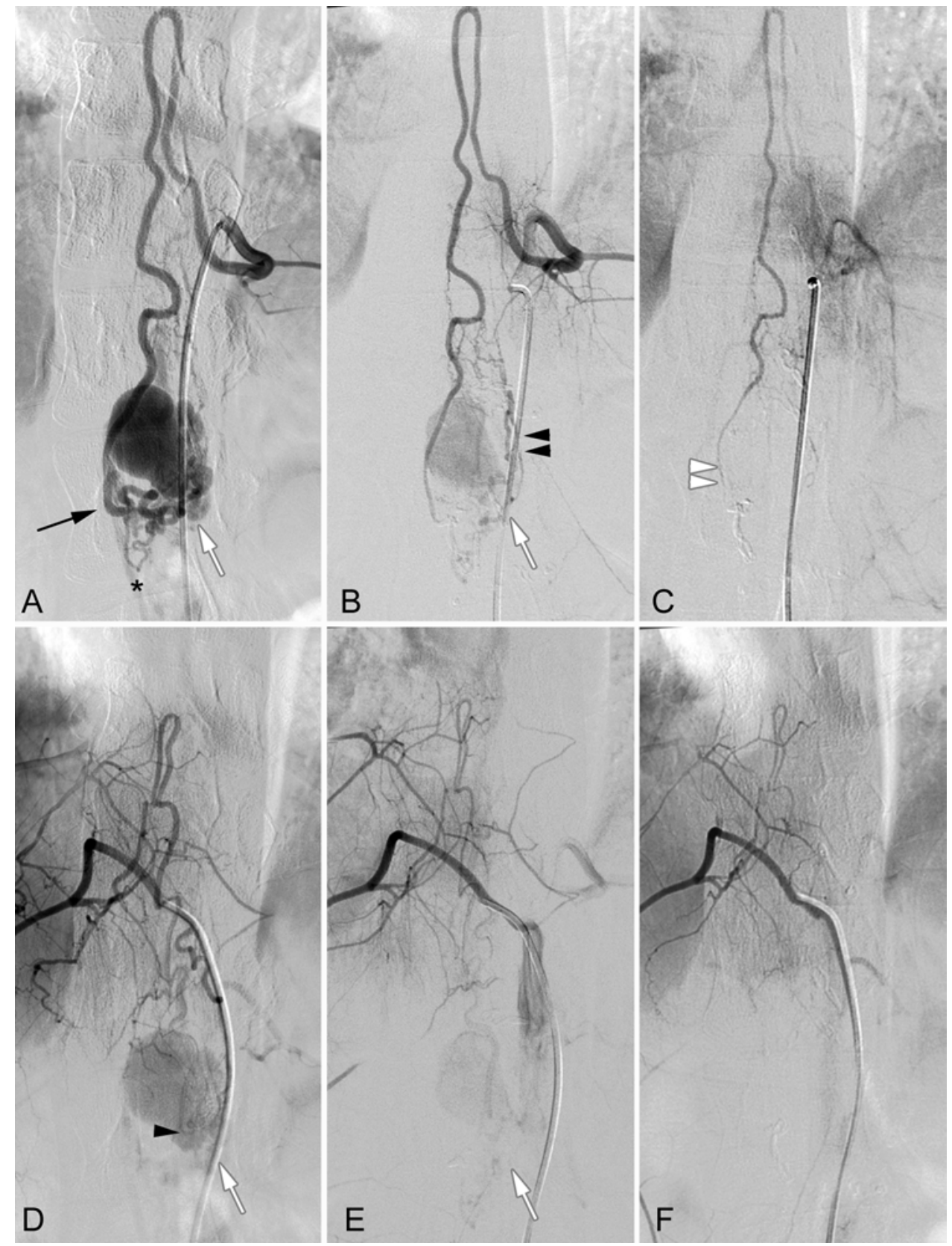

FIG. 5. Patient 7. Preoperative spinal angiograms (A and D) showing that the feeding arteries are pial branches of the ASA fed by the artery of Adamkiewicz from the left T-11 intercostal artery (black arrow, A). Note the arterial basket of the conus medullaris (asterisk, A). The AVF is also fed by pial branches of the PSA from the right T-11 intercostal artery (black arrowhead, D). The AVF is located on the ventrolateral surface of the conus medullaris (white arrows, $A, B, D$, and $E$ ). A giant varix is present and the draining veins are lumbar radiculomedullary veins. Spinal angiograms after the first surgery (B and $\mathbf{E}$ ) showing the new pial feeding arteries (double black arrowheads, B) and residual filling of the AVF. Spinal angiograms after second surgery (C and F) showing complete occlusion of the AVF and varix and normal filling of the ASA (double white arrowheads, C).

arterial ICG video angiography clearly demonstrated new pial feeding arteries after the known feeding arteries were coagulated. On the basis of ICG findings, multiple new feeding arteries were coagulated, resulting in complete occlusion of the AVF. Follow-up angiography showed complete occlusion of the AVF and the varix as well as normal filling of the ASA. The right lower-extremity pain and urinary incontinence were completely resolved postoperatively.

\section{Patient 9}

A 73-year-old man presented with progressive paraparesis and urinary incontinence due to venous hypertension from a perimedullary AVF on the filum terminale (Fig. 7).

A posterior approach was performed through a laminectomy at L-2. After opening the dura, the filum terminale with enlarged vessels was identified. Blood flow velocity of the filum vein was recorded using microvascular 

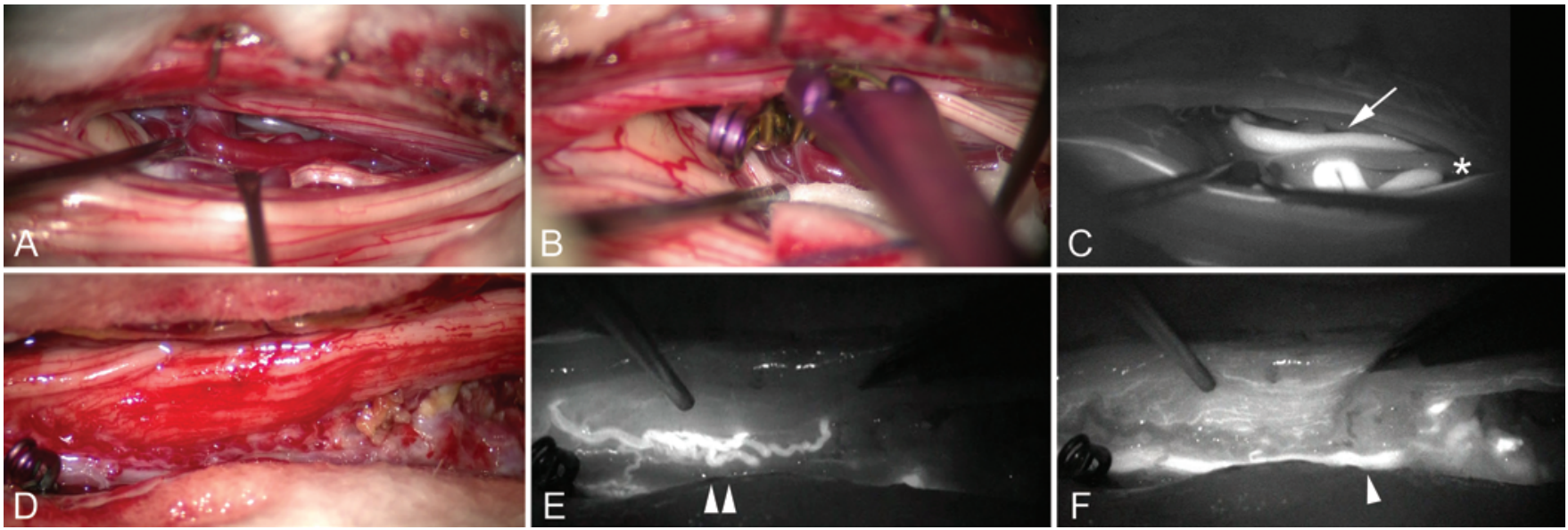

FIG. 6. Patient 7. Intraoperative photographs (A and B) showing clipping of the proximal and distal ASA for occlusion of bilateral pial feeding arteries from the ASA. The main pial feeding arteries branch off from the ASA in a cross shape. To block both feeders, the ASA is temporarily clipped just proximal and distal to these pial branches (B). ICG video angiogram (C) showing the occluded pial feeding artery and filling of the distal ASA with ascending flow (arrow, C) through the arterial basket of the conus medullaris (asterisk, C). An intraoperative photograph (D) showing pial vessels on the spinal cord surface. Selective intraarterial ICG video angiograms ( $E$ and $\mathbf{F}$ ) demonstrating arterial and venous phases. Note that the pial feeding artery from the artery of Adamkiewicz could be observed selectively in the arterial phase (double arrowheads, E) and the pial draining vein could be observed within a few seconds in the venous phase (arrowhead, F).

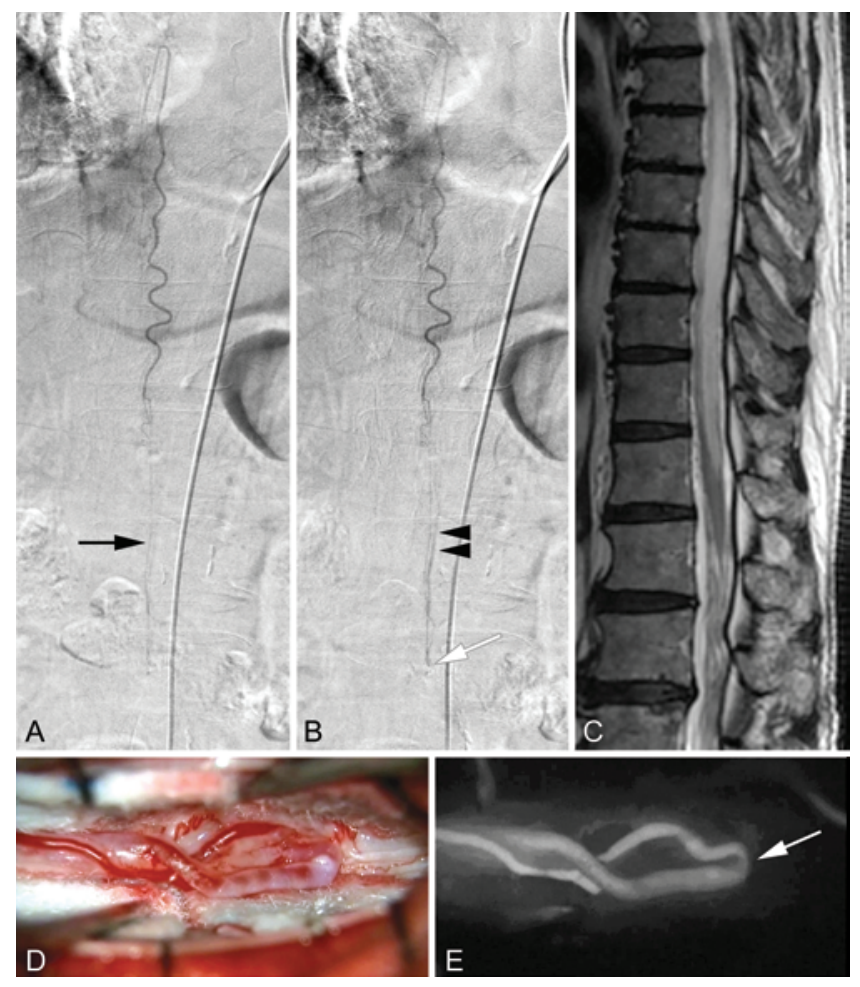

FIG. 7. Patient 9 . Spinal angiograms (A and $\mathbf{B}$ ) showing that the feeding artery is a filum terminale artery fed by the artery of Adamkiewicz from the T-10 intercostal artery (black arrow, A). The AVF is located on the filum terminale at L-2 (white arrow, B). The draining vein is a filum vein with ascending flow (black double arrowheads, B). Sagittal T2-weighted MR image (C) demonstrating high signal intensity of the spinal cord. Intraoperative photograph (D) and ICG video angiogram (E) showing the filum artery and AVF (white arrow, E).
Doppler (mean $1.4 \mathrm{~cm} / \mathrm{sec}$ ). After occluding the AVF by sectioning the filum, the color of the vein darkened and no abnormal flow was detected on microvascular Doppler. The results of ICG video angiography before and after sectioning the filum did not change the surgical procedure, because they corresponded with Doppler findings. Postoperative MRI showed no abnormal flow voids and a decrease in high T2 signal intensity. The degree of paraparesis remained unchanged postoperatively.

\section{Discussion}

This study found that intraoperative ICG video angiography had a significant impact on deciding surgical strategy in the microsurgical treatment of patients with spinal perimedullary AVFs. To the best of our knowledge, this work represents the first study to describe the intraoperative ICG angiographic findings of perimedullary AVF in detail.

In patients with perimedullary AVF, the surgical strategy could be changed during surgery on the basis of intraoperative ICG video angiography finding to correctly occlude the fistula, especially for perimedullary AVFs with multiple pial feeding arteries from the ASA and/or PSA on the cervical or lower spinal cord. Because pial feeding arteries in perimedullary AVF are so narrow, intraoperative blood flow assessment-of velocity or direction-is difficult when using other methods such as microvascular Doppler ultrasonography or intraoperative spinal angiography. However, intraoperative ICG video angiography provided real-time feedback of blood flow in small pial vessels. Occlusion of abnormal feeding arteries and patency of normal spinal arteries and veins can be evaluated in detail.

An exception was seen in some cases of perimedullary AVFs in which intraoperative ICG video angiography did not change the surgical strategy in patients with filum terminale AVFs. Identification of the filum terminale with an 
enlarged filum artery and vein was straightforward, since filum vessels are larger in diameter than spinal pial vessels. After occluding the AVF by sectioning the filum, blood flow velocity and direction is easily monitored using microvascular Doppler ultrasonography.

Blood flow assessment with ICG video angiography shows some limitations. The vessels must be exposed to the laser-fluorescence light from an imaging device integrated in the surgical microscope, since the light cannot pass through neural structures. Because most perimedullary AVFs are fed by pial branches from the ASA on the ventral spinal cord surface, all feeders and AV connections on the ventral spinal cord must be exposed to obtain fluorescent visualization of these vessels.

Several surgical techniques for an anterior approach have been reported in the cervical region. A transoral approach with removal of the dens at the C1-2 level ${ }^{4}$ and corpectomy at the $\mathrm{C} 3-\mathrm{T} 1$ levels,${ }^{8}$ but an anterior approach in the thoracic and lumbar regions is difficult and highly invasive. A posterolateral approach (i.e., laminotomy with medial facetectomy and spinal cord rotation technique) can be used to access the ventral spinal cord. ${ }^{9}$ Perimedullary AVFs on the ventrolateral surface of the spinal cord are a good indication for the posterolateral approach. With this technique, however, because the ventromedial limit of exposure is the ASA, contralateral branches from the ASA cannot be exposed, whereas ipsilateral pial branches can be blocked. For perimedullary AVFs with bilateral pial branches from the ASA, a double clipping technique (clipping of the ASA just proximal and distal to the pial feeding arteries) represents an alternative procedure in selected patients as described in Patient 7.

Lastly, we wish to emphasize that not only intraoperative ICG angiographic findings, but also other preoperative radiological findings including $3 \mathrm{D}$ reconstruction of rotational angiography ${ }^{15}$ can contribute to the microsurgical treatment of perimedullary AVF. We intend to report the clinical presentations, radiological findings, and treatment outcomes after open microsurgery for patients with perimedullary AVF in the future.

\section{Conclusions}

Intraoperative ICG video angiography can have a significant impact on deciding surgical strategy in the microsurgical treatment of spinal perimedullary AVFs.

\section{References}

1. Anson JA, Spetzler RF: Classification of spinal arteriovenous malformation and implications for treatment. BNI Q 8:2-8, 1992

2. Bakker NA, Uyttenboogaart M, Luijckx GJ, Eshghi OS, Mazuri A, Metzemaekers JD, et al: Recurrence rates after surgical or endovascular treatment of spinal dural arteriovenous fistulas: a meta-analysis. Neurosurgery 77:137-144, 2015

3. Cho KT, Lee DY, Chung CK, Han MH, Kim HJ: Treatment of spinal cord perimedullary arteriovenous fistula: embolization versus surgery. Neurosurgery 56:232-241, 2005

4. Friedrich H, Hänsel-Friedrich G, Zeumer H: Intramedullary vascular lesions in the high cervical region: transoral and dorsal surgical approach. Two case reports. Neurosurg Rev 13:65-71, 1990

5. Hanel RA, Nakaji P, Spetzler RF: Use of microscope-inte- grated near-infrared indocyanine green videoangiography in the surgical treatment of spinal dural arteriovenous fistulae. Neurosurgery 66:978-985, 2010

6. Heros RC, Debrun GM, Ojemann RG, Lasjaunias PL, Naessens PJ: Direct spinal arteriovenous fistula: a new type of spinal AVM. Case report. J Neurosurg 64:134-139, 1986

7. Hettige $S$, Walsh D: Indocyanine green video-angiography as an aid to surgical treatment of spinal dural arteriovenous fistulae. Acta Neurochir (Wien) 152:533-536, 2010

8. Hida K, Iwasaki Y, Ushikoshi S, Fujimoto S, Seki T, Miyasaka K: Corpectomy: a direct approach to perimedullary arteriovenous fistulas of the anterior cervical spinal cord. $\mathbf{J}$ Neurosurg 96 (2 Suppl):157-161, 2002

9. Martin NA, Khanna RK, Batzdorf U: Posterolateral cervical or thoracic approach with spinal cord rotation for vascular malformations or tumors of the ventrolateral spinal cord. J Neurosurg 83:254-261, 1995

10. Mourier KL, Gobin YP, George B, Lot G, Merland JJ: Intradural perimedullary arteriovenous fistulae: results of surgical and endovascular treatment in a series of 35 cases. Neurosurgery 32:885-891, 1993

11. Rosenblum B, Oldfield EH, Doppman JL, Di Chiro G: Spinal arteriovenous malformations: a comparison of dural arteriovenous fistulas and intradural AVM's in 81 patients. J Neurosurg 67:795-802, 1987

12. Schuette AJ, Cawley CM, Barrow DL: Indocyanine green videoangiography in the management of dural arteriovenous fistulae. Neurosurgery 67:658-662, 2010

13. Spiotta AM, Bain M, Moskowitz S: Intraoperative indocyanine green angiography as a substitute for conventional angiography in the surgical management of spinal dural arteriovenous fistulae. J Neurointerv Surg 3:182-185, 2011

14. Steinmetz MP, Chow MM, Krishnaney AA, AndrewsHinders D, Benzel EC, Masaryk TJ, et al: Outcome after the treatment of spinal dural arteriovenous fistulae: a contemporary single-institution series and meta-analysis. Neurosurgery 55:77-88, 2004

15. Takai K, Kin T, Oyama H, Iijima A, Shojima M, Nishido H, et al: The use of 3D computer graphics in the diagnosis and treatment of spinal vascular malformations. J Neurosurg Spine 15:654-659, 2011

16. Takai K, Kin T, Oyama H, Shojima M, Saito N: Threedimensional angioarchitecture of spinal dural arteriovenous fistulas, with special reference to the intradural retrograde venous drainage system. J Neurosurg Spine 18:398-408, 2013

17. Takai K, Komori T, Taniguchi M: Microvascular anatomy of spinal dural arteriovenous fistulas: arteriovenous connections and their relationships with the dura mater. J Neurosurg Spine 23:526-533, 2015

18. Takai K, Taniguchi M: Comparative analysis of spinal extradural arteriovenous fistulas with or without intradural venous drainage: a systematic literature review. Neurosurg Focus 32(5): $\mathrm{E} 8,2012$

19. Takai K, Taniguchi M: Microsurgical resection of an intramedullary glomus arteriovenous malformation in the high cervical spinal cord: retrograde dissection techniques of the nidus located between spinal tracts. Acta Neurochir (Wien) 157:1659-1664, 2015

20. Takai K, Usui M: Spontaneous thrombosis of a spinal conus perimedullary arteriovenous fistula. Case report. Neurol Med Chir (Tokyo) 52:103-106, 2012

21. Tsuruta W, Matsumaru Y, Miyachi S, Sakai N: Endovascular treatment of spinal vascular lesion in Japan: Japanese Registry of Neuroendovascular Therapy (JR-NET) and JR-NET2. Neurol Med Chir (Tokyo) 54:72-78, 2014

22. Yamamoto S, Kim P, Kurokawa R, Itoki K, Kawamoto S: Selective intraarterial injection of ICG for fluorescence angiography as a guide to extirpate perimedullary arteriovenous fistulas. Acta Neurochir (Wien) 154:457-463, 2012 


\section{Disclosures}

The authors report no conflict of interest concerning the materials or methods used in this study or the findings specified in this paper.

\section{Author Contributions}

Conception and design: Takai. Acquisition of data: Takai. Analysis and interpretation of data: Takai. Drafting the article: Takai. Critically revising the article: all authors. Reviewed submitted version of manuscript: all authors. Approved the final version of the manuscript on behalf of all authors: Takai. Study supervision: Takai.

\section{Correspondence}

Keisuke Takai, Department of Neurosurgery, Tokyo Metropolitan Neurological Hospital, 2-6-1, Musashidai, Fuchu, Tokyo, 183-

0042, Japan.email: takai-nsu@umin.ac.jp. 